\title{
Subarachnoid haemorrhage with negative initial neurovascular imaging: a systematic review and meta-analysis
}

\author{
Midhun Mohan ${ }^{1} \cdot$ Abdurrahman I. Islim ${ }^{1} \cdot$ Fahid T. Rasul $^{2} \cdot$ Ola Rominiyi $^{3} \cdot$ Ruth-Mary deSouza ${ }^{4} \cdot$ Michael T. C. Poon $^{5} \cdot$ \\ Aimun A. B. Jamjoom ${ }^{6}$. Angelos G. Kolias ${ }^{7}$. Julie Woodfield ${ }^{6} \cdot$ Krunal Patel $^{8} \cdot$ Aswin Chari $^{9,10}$ (D) Ramez Kirollos $^{7}$. \\ British Neurosurgical Trainee Research Collaborative
}

Received: 20 May 2019 / Accepted: 25 July 2019 / Published online: 13 August 2019

(C) The Author(s) 2019

\begin{abstract}
Background In patients with spontaneous subarachnoid haemorrhage (SAH), a vascular cause for the bleed is not always found on initial investigations. This study aimed to systematically evaluate the delayed investigation strategies and clinical outcomes in these cases, often described as "non-aneurysmal" SAH (naSAH).

Methods A systematic review was performed in concordance with the PRISMA checklist. Pooled proportions of primary outcome measures were estimated using a random-effects model.

Results Fifty-eight studies were included (4473 patients). The cohort was split into perimesencephalic naSAH (PnaSAH) (49.9\%), non-PnaSAH (44.7\%) and radiologically negative SAH identified on lumbar puncture (5.4\%). The commonest initial vascular imaging modality was digital subtraction angiography. A vascular abnormality was identified during delayed investigation in 3.9\% [95\% CI 1.9-6.6]. There was no uniform strategy for the timing or modality of delayed investigations. The pooled proportion of a favourable modified Rankin scale outcome (0-2) at 3-6 months following diagnosis was $92.0 \%$ [95\% CI 86.0 96.5]. Complications included re-bleeding (3.1\% [95\% CI 1.5-5.2]), hydrocephalus (16.0\% [95\% CI 11.2-21.4]), vasospasm (9.6\% [95\% CI 6.5-13.3]) and seizure (3.5\% [95\% CI 1.7-5.8]). Stratified by bleeding pattern, we demonstrate a higher rate of delayed diagnoses (13.6\% [95\% CI 7.4-21.3]), lower proportion of favourable functional outcome (87.2\% [95\% CI 80.1-92.9]) and higher risk of complications for non-PnaSAH patients.
\end{abstract}

Conference presentations

September 2017 - European Association of Neurosurgical Societies (EANS) 4th Annual Vascular Section Meeting - Nice, France. Oral presentation

September 2017-Society of British Neurological Surgeons (SBNS) Autumn Meeting - Liverpool, UK. Oral presentation

This article is part of the Topical Collection on Vascular Neurosurgery Other

Electronic supplementary material The online version of this article (https://doi.org/10.1007/s00701-019-04025-w) contains supplementary material, which is available to authorized users.

Aswin Chari

aswinchari@gmail.com

1 Department of Neurosurgery, The Walton Centre NHS Foundation Trust and University of Liverpool, Liverpool, UK

2 Department of Neurosurgery, Queen's Hospital, Romford, UK

3 Department of Neurosurgery, Sheffield Teaching Hospitals NHS Foundation Trust, Sheffield, UK

4 Institute of Neurology, University College London, London, UK

5 Usher Institute, University of Edinburgh, Edinburgh, UK
6 Department of Clinical Neurosciences, Western General Hospital, Edinburgh, UK

7 Division of Neurosurgery, Department of Clinical Neurosciences, University of Cambridge and Addenbrooke's Hospital, Cambridge, UK

8 Division of Neurosurgery, Krembil Research Institute, Toronto Western Hospital, University Health Network and University of Toronto, Toronto, Canada

9 Institute of Child Health, University College London, London, UK

10 Department of Neurosurgery, Great Ormond Street Hospital, Great Ormond Street, WC1N 3JH London, UK 
Conclusion This study highlights the heterogeneity in delayed investigations and outcomes for patients with naSAH, which may be influenced by the initial pattern of bleeding. Further multi-centre prospective studies are required to clarify optimal tailored management strategies for this heterogeneous group of patients.

Keywords Meta-analysis $\cdot$ Non-aneurysmal $\cdot$ Subarachnoid haemorrhage $\cdot$ Systematic review

\section{Introduction}

Spontaneous subarachnoid haemorrhage (SAH) is a lifethreatening condition most commonly caused by the rupture of an intracranial aneurysm [18, 49]. Once SAH has been confirmed, dedicated cerebrovascular imaging is performed to establish if there is an underlying vascular abnormality. CT angiography (CTA) is the most common initial cerebrovascular imaging modality used in the UK and Ireland [22], although digital subtraction angiography (DSA) is considered the gold standard [79]. Early detection of vascular abnormalities is important to direct timely treatment [23].

In up to $15 \%$ of patients with spontaneous $\mathrm{SAH}$, a structural cause for the bleeding is not identified on initial vascular imaging [23], and these are said to have experienced a nonaneurysmal SAH (naSAH). This group is heterogeneous and can be categorised into three subgroups, based on the distribution of blood on the initial non-contrast CT scan [70]:

- Perimesencephalic (PnaSAH): Defined as "blood present anterior to the midbrain with or without extension to the anterior ambient cistern or basal Sylvian fissure and without complete filling of the interhemispheric fissure or extension to the lateral Sylvian fissure".

- Non-perimesencephalic (non-PnaSAH): Acute blood is seen on the CT scan that is not confined to the PnaSAH territory.

- Radiologically negative: No acute blood on the CT scan. Diagnosis is made by spectrophotometric detection of a bilirubin peak in cerebrospinal fluid from a lumbar puncture (LP).

Although commonly accepted that patients with naSAH experience a "better" clinical course than aneurysmal SAH patients $[23,76]$, there is uncertainty regarding the functional outcomes and complications in these patients.

There also appears to be a wide variation in the investigation, follow-up and delayed pick-up rate of vascular abnormalities in naSAH patients [55]. This is particularly important since, although DSA is the gold-standard investigation, it represents an invasive procedure that is not without risk of complications [16]. Furthermore, subjecting a patient to multiple DSAs needs to be weighed carefully against the benefits and probability of identifying a cause for the bleed. Since CTA has become the first-line investigation, the added value of conventional DSA in these patients has also not been firmly established [29].

\section{Objectives}

This systematic review and meta-analysis aimed to summarise the literature on the investigation and management of naSAH by:

i. Synthesising estimates of complications risk and functional outcomes reported to date.

ii. Collating and comparing the various neurovascular imaging strategies and delayed diagnoses rates reported for this cohort of patients.

\section{Methods}

This systematic review was registered with PROSPERO (CRD42016035376) and has been reported in accordance with the PRISMA (Preferred Reporting Items for Systematic Reviews and Meta-Analyses) statement [46].

\section{Search strategy}

Medline, Web of Knowledge, Embase and the Cochrane Database of Systematic Reviews, via the National Institute's for Health and Care Excellence Health Databases Advanced Search (NICE HDAS) function, were inspected. The search strategy utilised was as follows:

i. ("non aneurysmal" OR "non-aneurysmal" OR "perimesencephalic" OR "angiogram-negative" OR "angiogram negative").

ii. ("subarachnoid hemorrhage" OR "subarachnoid haemorrhage" OR "SAH").

iii. i AND ii.

The bibliographies of accepted papers were examined for additional articles not identified in the initial search. The search was last updated in April 2018.

\section{Study selection}

The resulting titles and abstracts were screened independently by two authors (M.M. and O.R.) using the patients, intervention, comparator, outcomes and study design (PICOS) criteria below. All decisions about an article's inclusion or exclusion 
were blinded. Where disagreements occurred, a senior author (A.C.) was consulted.

\section{PICOS criteria}

- Patients: Adults ( $\geq 16$ years) with a diagnosis of spontaneous SAH (either by CT brain or LP) and negative initial neurovascular imaging. The term "initial vascular imaging" was defined as one or more dedicated cerebrovascular imaging techniques (CTA, magnetic resonance angiography [MRA] or DSA) performed within $72 \mathrm{~h}$ of ictus. If no time-period was specified in the study, but the study stated, "initial imaging", this was taken as the form of initial imaging strategy used. Traumatic SAH was excluded.

- Interventions/Comparators: Not required.

- Outcomes:

i. Primary: Functional outcomes at 6 months post-ictus.

ii. Secondary: Functional outcomes at discharge and $\geq$ 1 year post-ictus, delayed diagnoses (including timing and modality of imaging that detected the abnormality), complications (re-bleeding, hydrocephalus, vasospasm, seizure or serum sodium $\left(\mathrm{Na}^{+}\right)$abnormality [hypo- and hypernatremia]), length of hospital stay, cost and patient perception of information provided by clinical team. Delayed diagnosis was defined as the diagnosis of an aneurysm or any other vascular abnormality that could explain the initial bleed, not identified by the initial vascular imaging strategy but subsequently identified on repeat imaging.

- Study design: Full-text English-language publications of studies with $\geq 10$ patients.

\section{Data extraction}

Demographics data, presenting bleeding pattern (PnaSAH, non-PnaSAH, radiologically negative) and initial neurovascular imaging strategies were extracted independently by two authors (M.M. and O.R.) using a standardised proforma, with disagreements resolved via further review and discussion with a senior author (A.C.).

\section{Data synthesis}

\section{Presenting clinical-radiological status}

The initial clinical grade recorded either using the World Federation of Neurosurgical Societies (WFNS) or Hunt and Hess grading system, and radiological grade via
Fisher or the modified Fisher grading system were noted. For pooled analyses, both clinical measures were dichotomised into good (grades 1-3) and poor (grades 4-5) and modified Fisher grades were translated back into the original grading system (Modified Fisher $0 \rightarrow$ Fisher $1,1 \rightarrow 2,3 \rightarrow 3,2 \& 4 \rightarrow 4)$.

\section{Functional outcomes}

These were examined at three time-points - at discharge (or early outcome), 3-6 months and at $\geq 1$ year. Outcomes were dichotomised into favourable (modified Rankin scale [mRS] 0-2) and unfavourable (mRS 3-6).

\section{Post-naSAH complications}

Re-bleeding was split into early (prior to discharge or < 14 days) and late based on the common definitions used by the included studies. Hydrocephalus requiring surgical intervention was categorised into temporary (requiring temporary external ventricular drainage only) and long term (requiring CSF shunting). Vasospasm was sub-divided into radiological and clinical (i.e. delayed ischemic neurological deficit [DIND]).

\section{Statistical analysis}

Study-level data were collated and presented as number (percentage), mean (standard deviation [SD]) or median (interquartile range $[\mathrm{IQR}]$ ) as appropriate. For each outcome of interest, the primary summary statistic extracted from the included studies was the incidence risk or proportion (number of events/total number of patients). To obtain an overall summary statistic (95\% confidence interval [95\% CI]), the following steps were followed:

i. The proportions of the included studies were transformed using the Freeman-Tukey double arcsine method [26]. This allowed for normalisation and variance stabilisation of data with a binomial distribution and enabled the use of studies with null event rates as to represent the whole study population.

ii. Transformed proportions were combined using an inverse-variance weighted random-effects meta-analysis model as described by DerSimonian and Laird [19]. For ease of interpretation, the aggregated number of the transformed proportions was converted back to the original scale (inverse-variance). To account for suspected methodological variation and population diversity, a random-effects model, which assumes unequal variance between studies, was used to distribute statistical weighting more conservatively; 


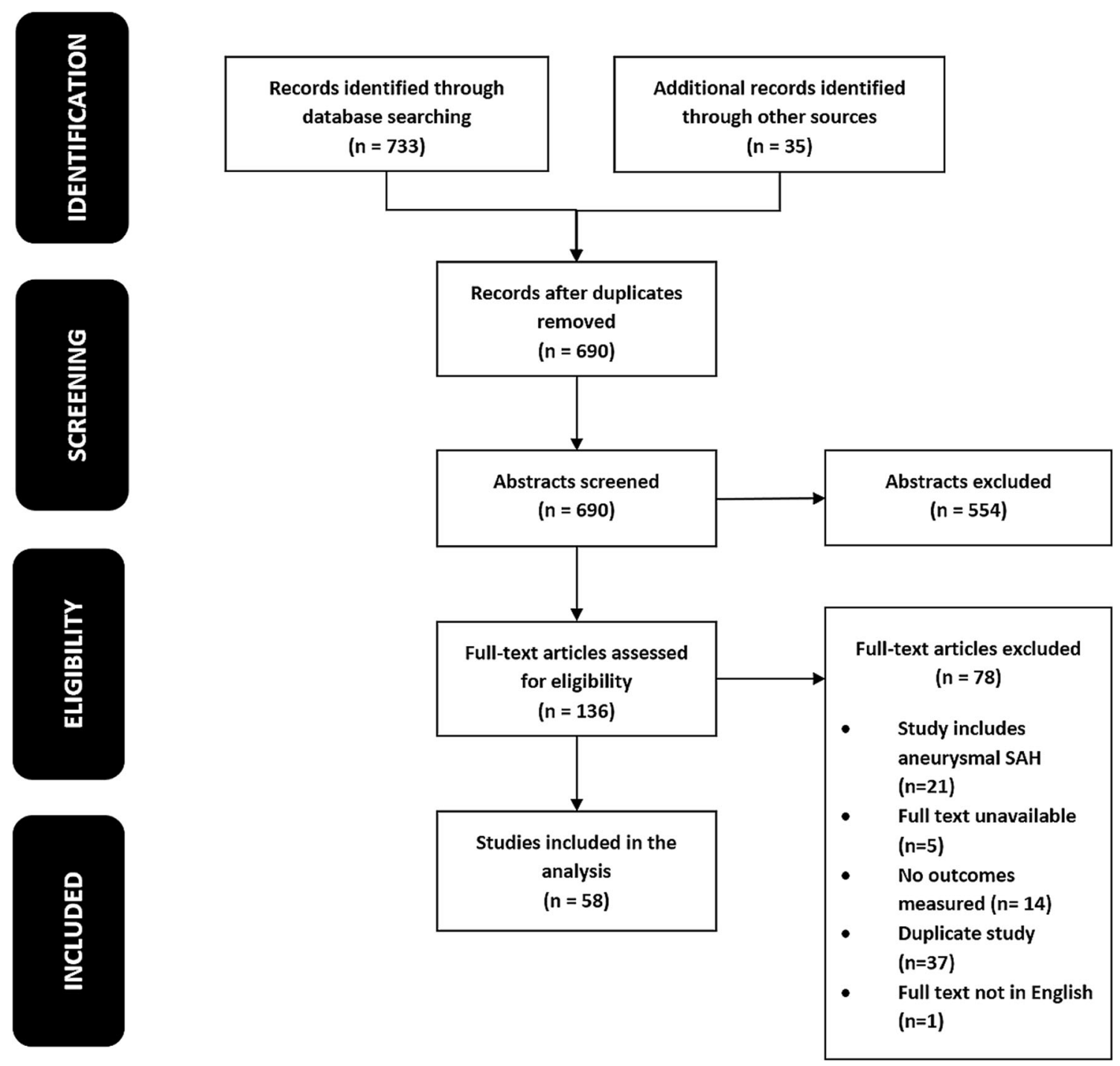

Fig. 1 PRISMA flow chart

small studies were not discounted, and larger studies were less likely to dominate the analysis.

Variation across studies, owing to heterogeneity rather than chance, was estimated using the $I^{2}$ statistic and categorised into low $(\leq 25 \%)$, moderate $(\sim 50 \%)$ and high $(\geq 75 \%)$. SPSS $®$ v24.0 and StatsDirect $®$ v3.0 were used for statistical analyses.

\section{Quality assessment}

The NIH Quality Assessment Tool for Observational Cohort and Cross-Sectional Studies was used to assess risk of bias (Fig. e-1). All quality assessments were undertaken in a blinded fashion by two authors (M.M. and A.I.I.). Where discrepancies arose, a third author (A.C.) was consulted.

\section{Results}

A total of 58 studies were included, totalling 4473 patients (Fig. 1). Of these, 19 were prospective [1, 2, 9, 10, 20, 21, 32, $38,39,41-44,47,48,50,51,53,54], 37$ were retrospective [4, 6-8, 12-15, 17, 24, 25, 27, 28, 30, 31, 34-36, 40, 57, 58, 61, 63, $66-69,71-76,78,80-82]$ and two studies [11, 52] had both prospective and retrospective data (Table e-1). Quality assessment results are summarised in Fig. e-2. Three studies $(5.17 \%)$ were "poor", 31 (53.4\%) were "fair" and 24 (41.4\%) were "good".

\section{Demographics and pattern of bleeding}

Among the 49 studies (3853 patients) in which demographic data were reported, the weighted mean age of included subjects was 53.8 years. Forty-five studies (3493 patients) 
reported sex and $54.3 \%$ were male (Table e-1). Forty-five studies (3530 patients) sub-classified naSAH by pattern of bleeding; 49.9\% (1763/3530) patients had a PnaSAH, $44.7 \%$ (1577/3530) patients had a non-PnaSAH and 5.4\% (190/ 3530) had radiologically negative $\mathrm{SAH}$.

Pooled proportions of presenting WFNS grade, Hunt and Hess grade and Fisher grade are shown in Fig. 2. A higher proportion of non-PnaSAH patients had poor presenting clinical and radiological grade.

\section{Initial vascular imaging and delayed diagnoses}

The initial vascular imaging strategies, reported in 50 studies, were heterogenous-DSA only (64\%), CTA + DSA (16\%), DSA + MRA (6\%), CTA + DSA + MRA (6\%), CTA only $(4 \%)$ and DSA or CTA (4\%).

Eighteen studies reported delayed diagnoses data. From a total of 1965 patients, 89 patients were found to have a vascular abnormality at a delayed investigation (range from 0 to 17.3\%; Table e-2), yielding a pooled proportion of $3.9 \%[95 \%$ CI 1.9-6.6, $I^{2}=85.6 \%$ ] (Fig. 3). Details regarding the timing of the delayed imaging are available in Table e-2; timing was not reported in 14/18 (77.8\%) studies and the earliest and latest investigations in the four other studies were reported at $\leq 72 \mathrm{~h}$ and $\geq 1$ year from ictus. Anterior circulation aneurysm $(60.6 \%)$ was the most commonly reported diagnosis (Table 1).

The pooled rate of delayed diagnoses was $3.9 \%$ when DSA alone was the initial vascular imaging strategy, $1.7 \%$ when DSA and CTA were used and $7.8 \%$ when DSA and MRI/A (including spine) were used (Fig. 4). No studies reported delayed diagnoses data following CTA alone. The modality on which the delayed diagnoses were identified was DSA in most of the cases, although some were also identified on CTA (Fig. 4). Seven studies reported delayed diagnoses stratified by bleeding pattern: $3.5 \%$ [95\% CI 1.0-7.5, $I^{2}=28.3 \%$ ] for PnaSAH and $13.6 \%$ [95\% CI 7.4-21.3, $I^{2}=$ $74.3 \%$ ] for non-PnaSAH. One study reported a single abnormality found on delayed imaging in 10 patients with radiologically negative SAH (10.0\%).

\section{Functional outcomes}

Functional outcomes were reported in 17/58 studies (1402 patients). At discharge, outcomes were available for 273 patients ( 5 studies) and 177 had a favourable outcome (pooled proportion $86.5 \%$ [95\% CI 80.3-91.6, $\left.I^{2}=61.6 \%\right]$ ]). At 3-6 months, 685/ 774 patients ( 7 studies) had a favourable outcome (pooled proportion $92.0 \%$ [95\% CI 86.0-96.5, $\left.I^{2}=85.1 \%\right]$ ). Two studies (190 patients) reported long-term outcomes ( $\geq 1$ year); 171 had a favourable outcome (pooled proportion $89.6 \%$ [95\% CI 86.6$\left.97.1, I^{2}=0 \%\right]$ ). Outcomes stratified by bleeding pattern highlight that the likelihood of a poor outcome at 3-6 months and $\geq 1$ year was double in non-PnaSAH patients when compared to PnaSAH patients (Fig. 5).

\section{Complications and length of hospital stay}

Complications data were reported in $37 / 58$ studies (3133 patients). Re-bleeding was reported in 23/58 studies (1675 patients) with a pooled risk of $3.1 \%$ [95\% CI 1.5-5.2]. Hydrocephalus was reported in 28 studies (2399 patients) and the pooled risk was 16.0\% [95\% CI 11.2-21.4]. The pooled risk of vasospasm, reported in 19 studies (1926 patients), was 9.6\% [95\% CI $6.5-$ 13.3]. Five studies (379 patients) reported incidence of seizures with a pooled risk of $3.5 \%$ [95\% CI 1.7-5.8], although they did not specify whether these were early or late. The pooled risk of $\mathrm{Na}^{+}$abnormalities, available in eight studies (547 patients), was $2.7 \%$ [95\% CI $0.6-$ 6.2]. Stratified by pattern of bleed, the risk of the above-mentioned complications in non-PnaSAH patients, except for $\mathrm{Na}^{+}$abnormalities, was about double that of the PnaSAH cohort (Table 2).

Nine studies (608 patients) reported data regarding length of stay (Table 3) with the shortest median and mean for patients with PnaSAH being 10 and 8.3 days, respectively. For patients with non-PnaSAH, the shortest median and mean were 8.3 and 4 days, respectively. One study reported a median length of stay of 5 days for patients with radiologically negative SAH. The heterogeneity of formats in the reporting of length of stay means that meta-analysis could not be performed.

\section{Additional outcomes}

No data were available in the included studies to inform two outcomes that were stated in our protocol, namely cost and patient perception of information provided by the clinical team.

Table 1 Delayed diagnoses details available for 66 patients

\begin{tabular}{lc}
\hline Diagnosis & $N(\%)$ \\
\hline Anterior circulation aneurysm & $40(60.6)$ \\
Posterior circulation aneurysm & $15(22.7)$ \\
Aneurysm $^{\mathrm{a}}$ & $2(3.0)$ \\
Posterior circulation pseudoaneurysm $_{\text {Infundibulum }^{\mathrm{a}}}$ & $2(3.0)$ \\
Spinal AVM $^{\mathrm{a}}$ & $2(3.0)$ \\
Brain AVM $^{\mathrm{a}}$ & $1(1.5)$ \\
Brain cavernoma $^{\mathrm{a}}$ & $1(1.5)$ \\
Vertebral artery dissection $^{\mathrm{AV} \text { fistula }}$ & $1(1.5)$ \\
\hline
\end{tabular}

$A V$ arteriovenous, $A V M$ arteriovenous malformation

${ }^{\mathrm{a}}$ Location unspecified 
a

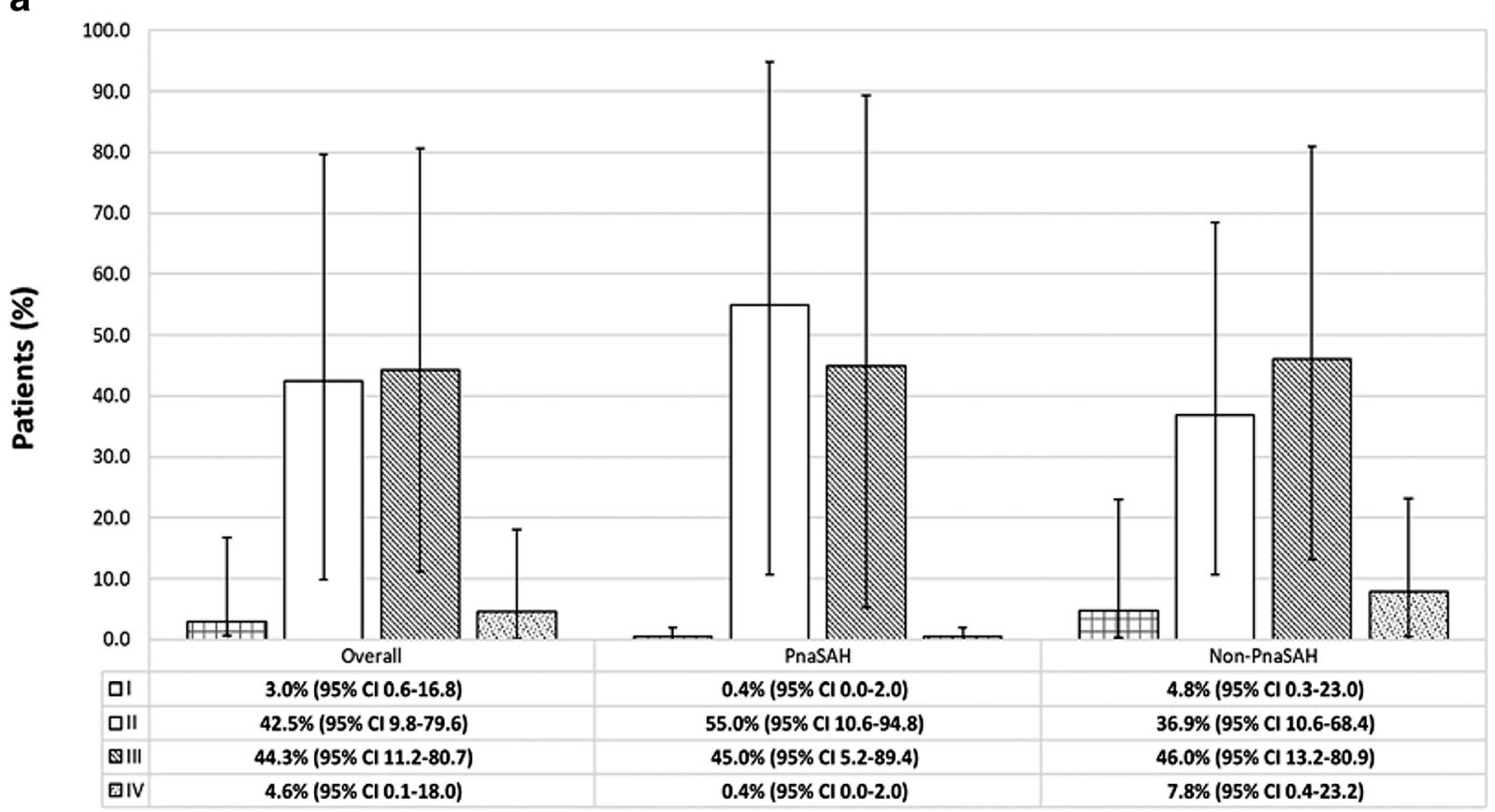

b

미

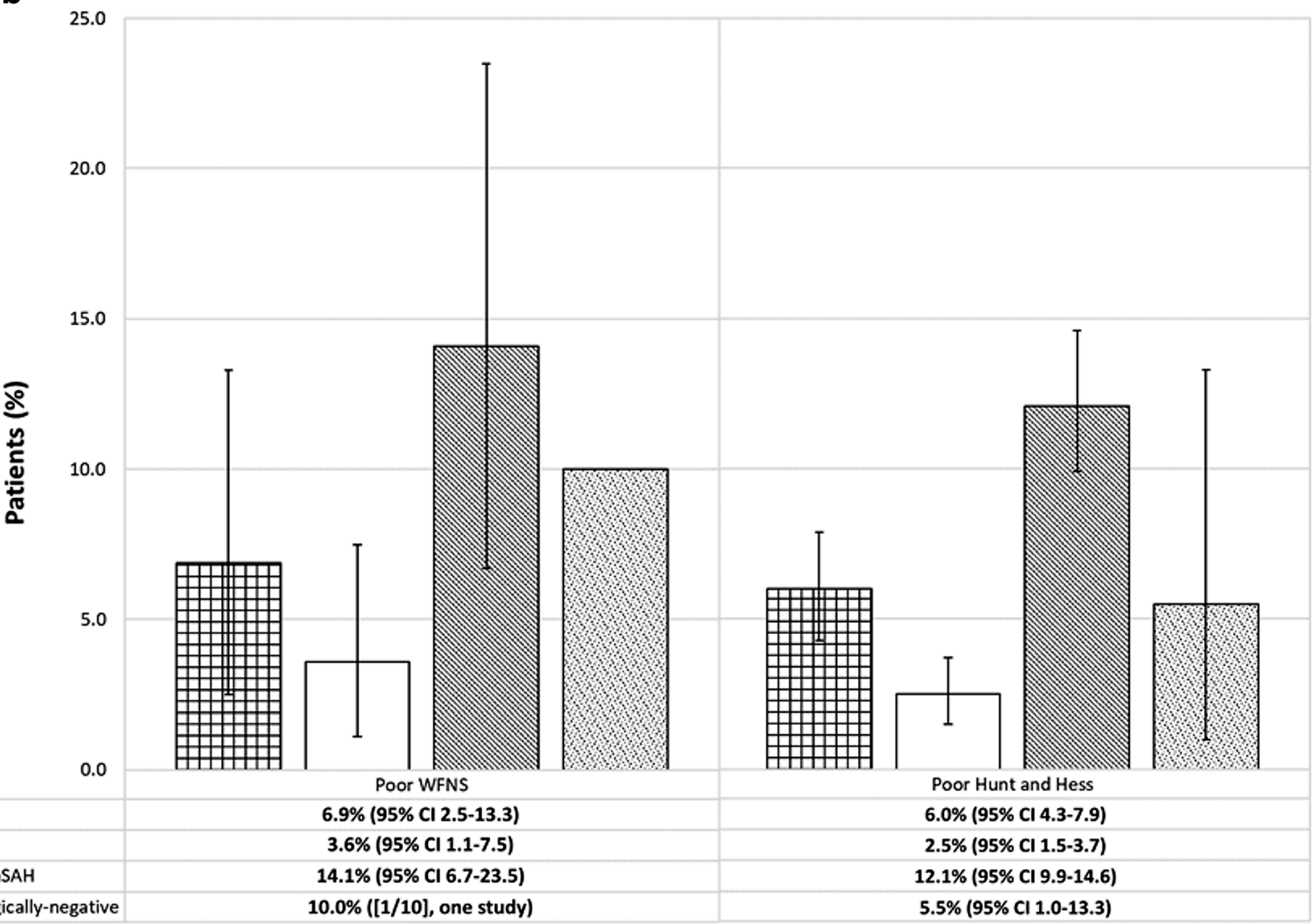

mOverall $\square$ PnaSAH \&Non-PnaSAH @Radiologically-negative

Fig. 2 a Presenting Fisher grade stratified by bleeding pattern. Pooled percentages were informed by three studies (350 patients). b Presenting WFNS and Hunt and Hess grades stratified by bleeding pattern. Pooled
WFNS percentages were informed by nine studies (594 patients). Pooled Hunt and Hess percentages were informed by 19 studies (1545 patients) 


\section{Discussion}

This systematic review highlights the heterogeneity in presentation, functional outcomes and frequency of delayed diagnoses of naSAH patients, which, given its increasing incidence [37], emphasises a need to clarify optimal management strategies. Specifically, it is an important step in highlighting the need for tailored management that takes into consideration the higher rate of delayed diagnoses and complications in the nonPnaSAH cohort.

This review raises several interesting findings. The primary outcome of interest in our protocol was functional outcome at 6 months post-ictus as we sought to better understand outcomes in a group of patients who are generally thought to have "good" functional outcomes. The results suggest that non-PnaSAH patients had double the proportion of unfavourable outcomes at $3-6$ months $(12.8$ vs $6.1 \%)$ and $\geq$ 1 year (14.4 vs $7.3 \%$ ) when compared to PnaSAH patients and higher rate of complications including re-bleeding (3.5 vs $1.1 \%$ ), hydrocephalus (25.5 vs $9.0 \%$ ), vasospasm (13.5 vs $6.9 \%$ ) and seizures (5.2 vs $2.5 \%$ ); interestingly, the rates of sodium abnormalities were similar between the groups ( $2.2 \mathrm{vs}$
2.3\%). This subgroup of patients may benefit from early transfer to a neurosurgical unit for the prevention and management of potential complications. This closely mirrors the findings of other publications, which suggest similar outcome and complication rates to patients with aneurysmal SAH [3]. There is evidence that, even in PnaSAH, patients may have cognitive or neuropsychogical impairment that precludes return to their premorbid functional state [50,59]. Some of these patients may require specialised neurological rehabilitation and identification of the long-term neuropsychological, cognitive and quality-of-life outcomes is clearly warranted. Identification of these outcomes may also have implications for resource provision in terms of longer-term neurological rehabilitation.

It also shows that clinicians use diverse neurovascular investigation strategies before classifying patients as "non-aneurysmal". A large proportion of studies utilised DSA as part of the first-line strategy and only two studies used CTA solely as the initial imaging tool, both of which did not report their rates of delayed diagnoses. Contemporary practice commonly involves CTA as a first-line investigation, which has been shown to have high specificity and sensitivity [77]. In addition, the potential risks of a DSA need to be considered but
Fig. 3 Forest plot showing the risk of delayed diagnosis $(95 \%$ CI). Horizontal lines denote $95 \%$ CIs; solid squares represent the point estimate of each study and the diamond represents the pooled proportion of delayed diagnoses (3.9\% [95\% CI 1.9-6.6, $I^{2}=$ $85.6 \%]$ ). The size of the solid squares is proportional to the weight of the study

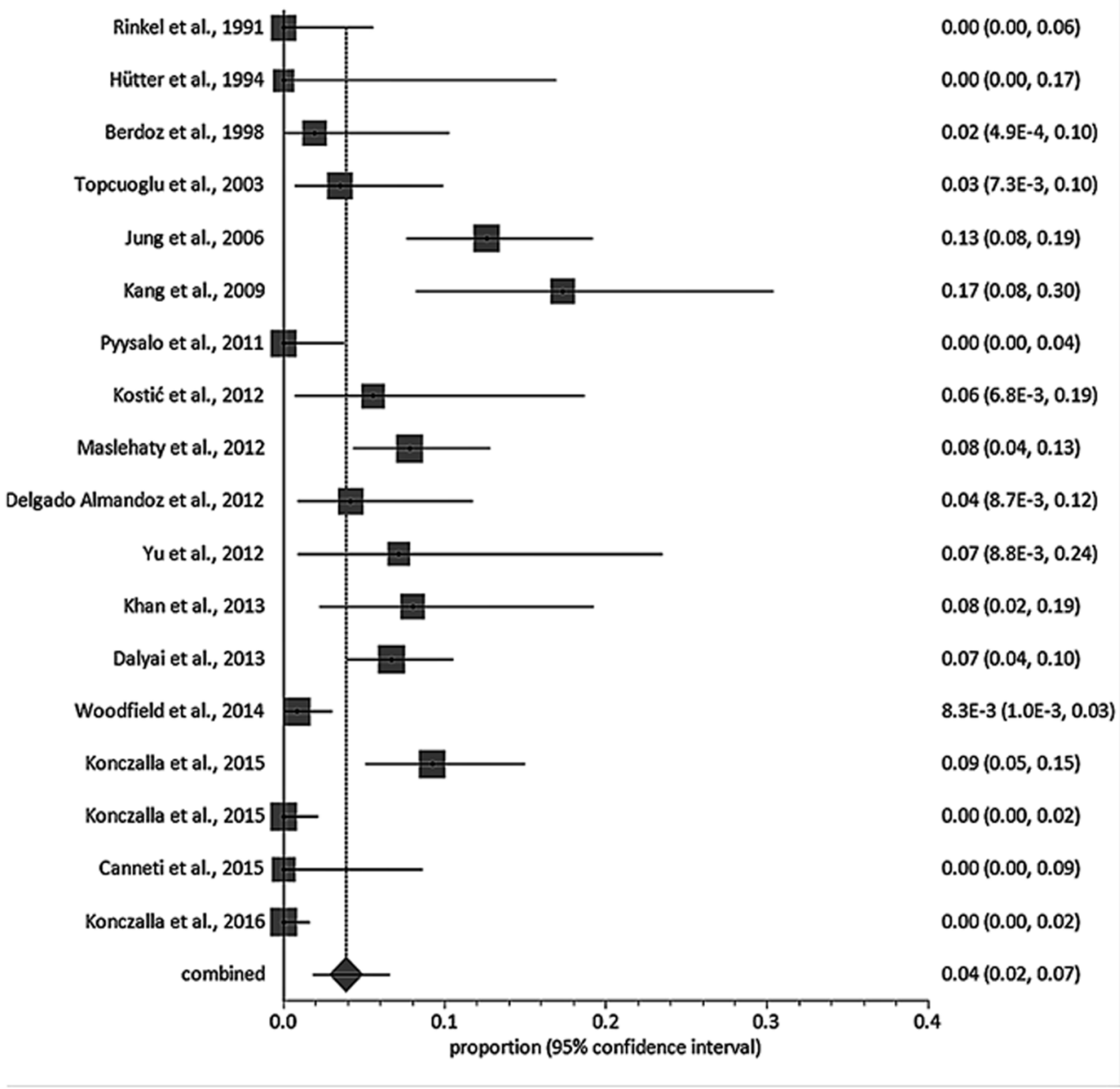




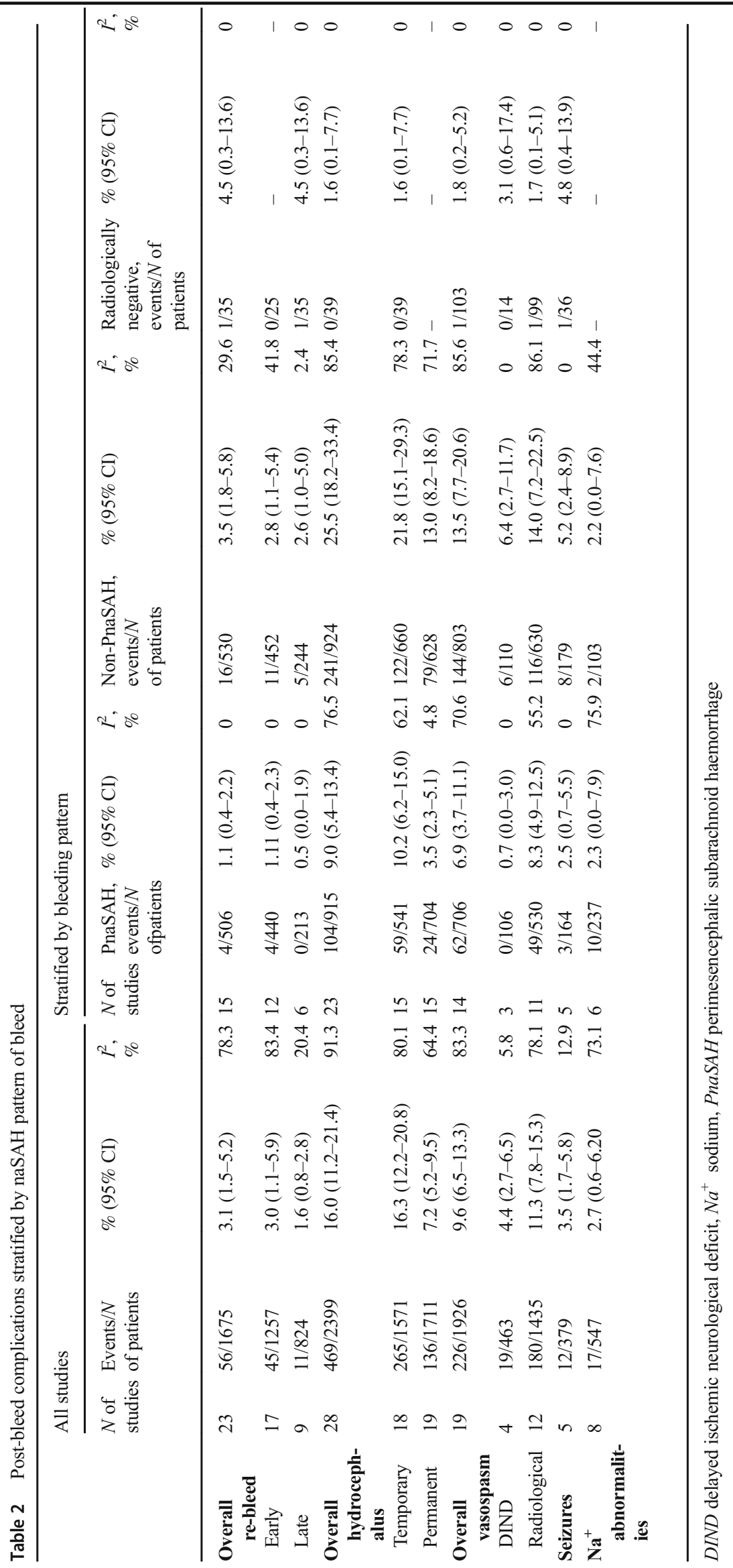


were not reported by any of the studies in this review. In an era of centralised neurosurgical and neuroradiological services and high quality CTA, it seems pertinent to evaluate the added benefits of early DSA (which requires transfer of patients to regional neurosciences centre) if the patient has a low-risk pattern of bleeding (i.e. PnaSAH) and the initial CTA is of sufficient quality and does not identify a vascular abnormality [5]. The studies included in this review did not permit such an assessment. It is interesting, however, to note that the delayed pick-up rate of vascular abnormalities in patients who had had a CTA and DSA as their initial strategy was as low as $1.7 \%$.

Another poorly understood entity in acute SAH, especially in the context of a negative CTA, is the role of early MR imaging, including MRA and spinal imaging. Interestingly, our study identified a high delayed diagnosis rate of $7.8 \%$ in patients who had had initial DSA and MRI/A and the reasons behind this warrant further exploration. A recent study showed high sensitivities $(98.2 \%)$ but slightly lower specificities $(91 \%)$ of 3.0 T MRA in detecting vascular abnormalities in a large cohort of acute good-grade $\mathrm{SAH}$ patients, indicating that it could be a useful tool even in the acute setting [45].

To our knowledge, there are no published guidelines as to which imaging modalities to use for repeat imaging and the timeframe for when this repeat imaging should be undertaken. We found that delayed diagnoses were almost $4 \times$ more prevalent in the non-PnaSAH group compared to the PnaSAH group and so it would seem logical to investigate patients with non-PnaSAH more comprehensively and as early as possible to facilitate early treatment of vascular abnormalities, avoid re-bleeding events and thereby optimise functional outcomes. Other risk factors for delayed diagnosis, that warrant early aggressive investigation, also require characterisation. It is interesting to note that the majority of delayed diagnoses were identified on follow-up DSA, although this may simply be a consequence of DSA being the predominant investigation used in the delayed setting; the yield of non-invasive techniques in this delayed setting also requires evaluation. For the time-being, and in view of the marked heterogeneity of

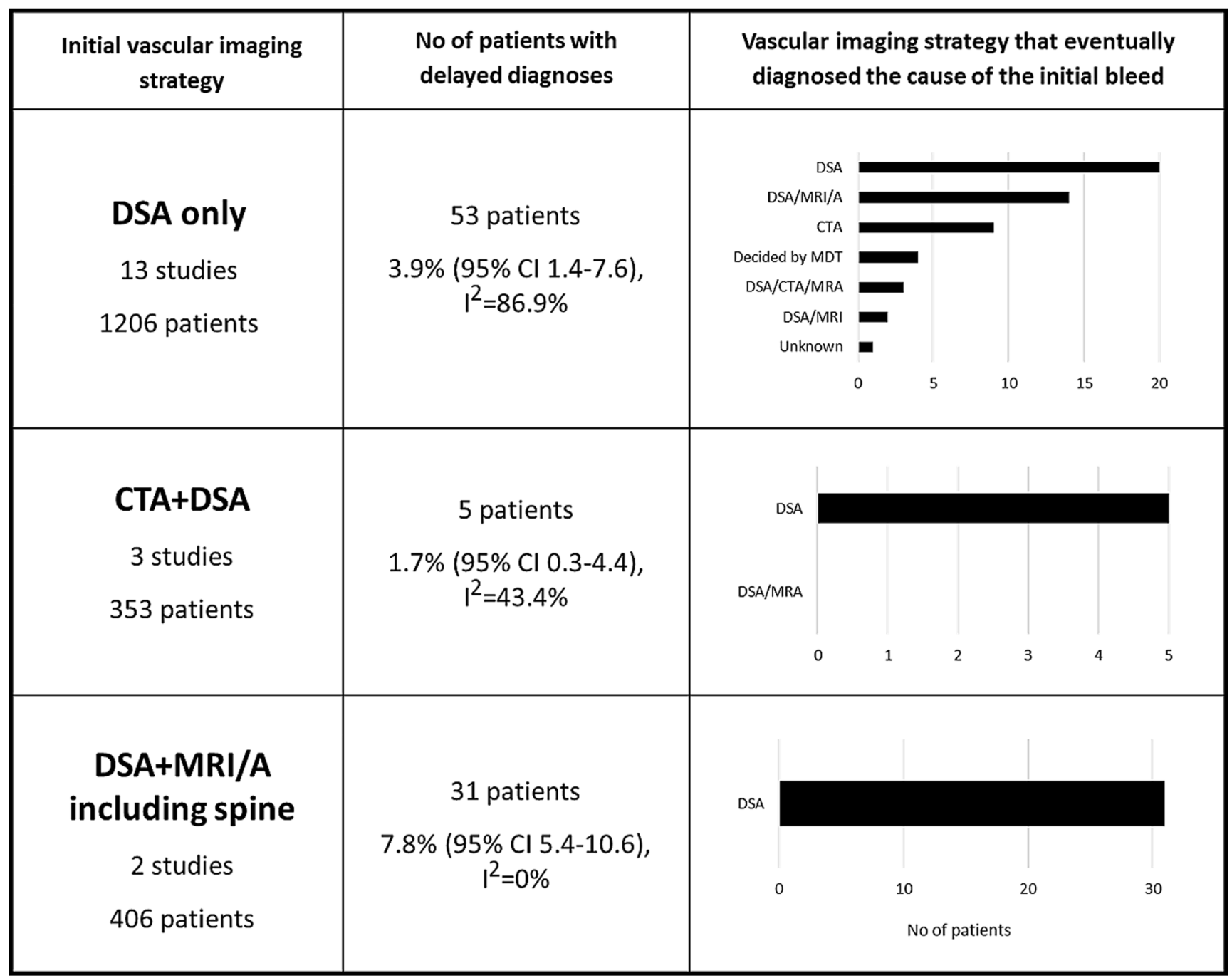

Fig. 4 Risk of delayed diagnosis stratified by initial investigation strategy and details of imaging modalities by which delayed diagnoses were identified 


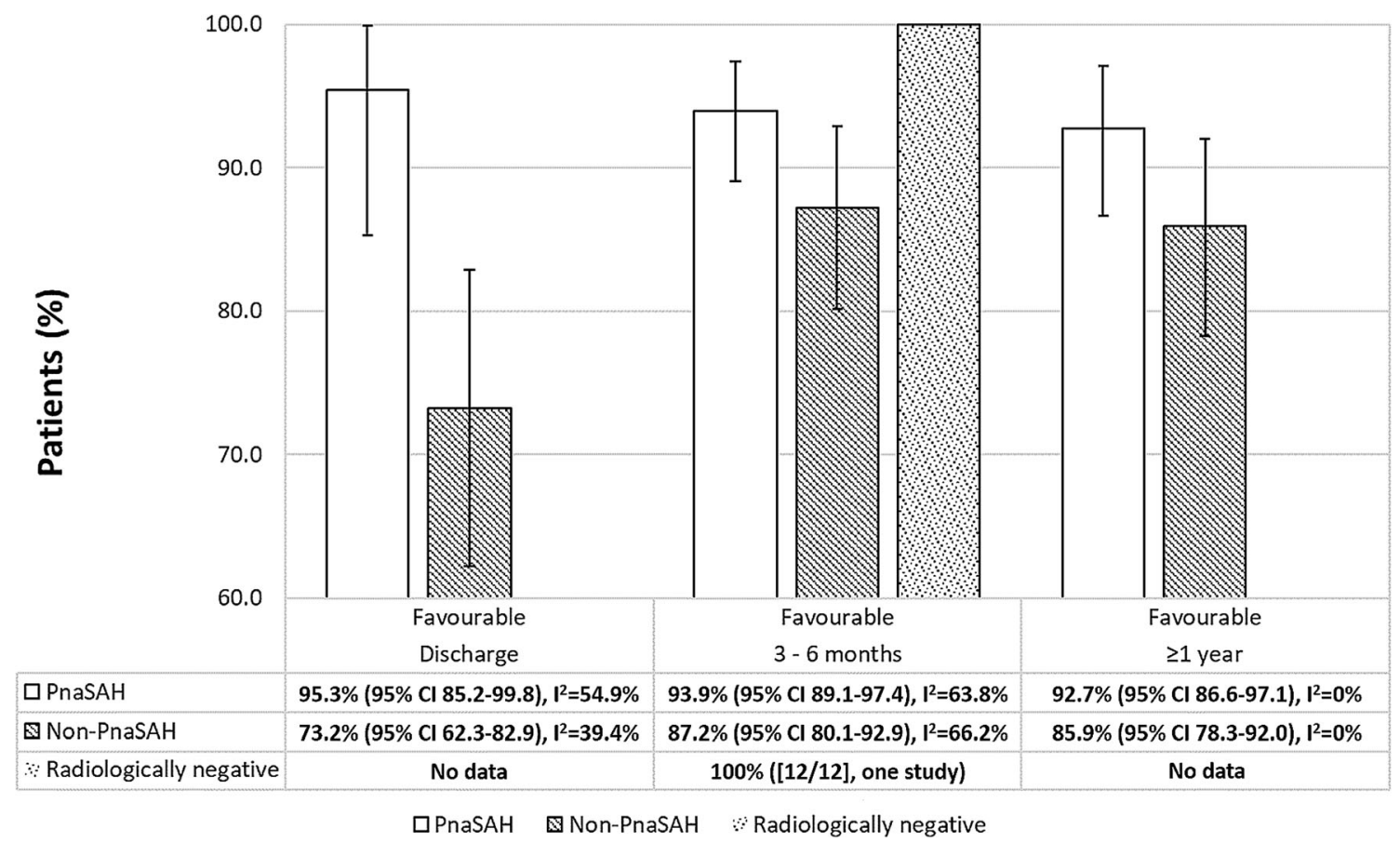

Fig. 5 Modified Rankin scale outcomes stratified by bleeding pattern

initial investigation regimens, and the poor reporting of timing of delayed imaging and diagnoses, specific recommendations regarding follow-up imaging cannot be made and tailored to each bleeding pattern.

These data make a strong case for a large-scale multi-centre prospective observational studies to better understand the nuances of delayed diagnoses, functional outcomes and complications in patients with naSAH. Studying a large consecutive prospective cohort with individual patient-level data will allow inferences to be made about the utility of various imaging modalities, particularly if Bayesian statistical models are incorporated, which allow assessments of probabilities of specified outcomes (functional outcome, complication, delayed diagnosis) based on priors. This will then enable us to formulate nuanced individualised strategies that optimise patient outcomes allowing stratification of patients that may require

Table 3 Details regarding length of stay (days) for patients with naSAH stratified by pattern of bleed

\begin{tabular}{|c|c|c|c|c|c|c|c|c|}
\hline Study & Overall, $N$ & LOS & PnaSAH, $N$ & LOS & Non-PnaSAH, $N$ & LOS & $\begin{array}{l}\text { Radiologically } \\
\text { negative, } N\end{array}$ & LOS \\
\hline Georgen et al., 1993 & 18 & NR & 9 & $12^{\mathrm{a}}$ & NR & NA & NR & NA \\
\hline Andaluz et al., 2008 & 92 & $6.3^{\mathrm{b}}$ & 45 & $4.3^{\mathrm{b}}$ & 47 & $8.3^{\mathrm{b}}$ & 0 & NA \\
\hline Beseoglu et al., 2010 & 21 & $15.3^{\mathrm{b}}$ & 12 & $11.2^{\mathrm{b}}$ & 9 & $20.7^{\mathrm{b}}$ & 0 & NA \\
\hline Nayak et al., 2010 & 190 & $14^{\mathrm{c}}$ & NR & NA & NR & NA & NR & NA \\
\hline \multirow[t]{3}{*}{ Delgado Almandoz et al., 2012} & 25 & $2-7^{\mathrm{a}}$ & 15 & $2-7^{\mathrm{a}}$ & 8 & $2-7^{\mathrm{a}}$ & 2 & $2-7$ \\
\hline & 34 & $8-14^{\mathrm{a}}$ & 12 & $8-14^{\mathrm{a}}$ & 20 & $8-14^{\mathrm{a}}$ & 2 & $8-14$ \\
\hline & 13 & $\geq 15^{\mathrm{a}}$ & 2 & $\geq 15^{\mathrm{a}}$ & 11 & $\geq 15^{\mathrm{a}}$ & 0 & $\geq 15$ \\
\hline Boswell et al., 2013 & 31 & NR & 14 & $12.5^{\mathrm{b}}$ & 16 & $13.2^{\mathrm{b}}$ & 1 & NR \\
\hline Khan et al., 2013 & 50 & NR & $17^{\mathrm{c}}$ & 8.3 & $23^{\mathrm{c}}$ & 10 & $10^{\mathrm{c}}$ & 5 \\
\hline Muehlschlegel et al., 2013 & 93 & $11^{\mathrm{c}}$ & 36 & NR & 48 & NR & 9 & NR \\
\hline Canneti et al., 2015 & 41 & $21.1^{\mathrm{b}}$ & 17 & $17^{\mathrm{b}}$ & 24 & $24^{\mathrm{b}}$ & 0 & NA \\
\hline
\end{tabular}

LOS length of stay, NA not applicable, $N R$ not reported

${ }^{\mathrm{a}}$ Discharged within

${ }^{\mathrm{b}}$ Mean

${ }^{\mathrm{c}}$ Median 
early and/or delayed angiography, or management of acute or chronic neurological complications. Furthermore, economic analyses need to be undertaken to specifically address the issue of patient transfers to specialist neuroscience units for further investigation and management, an aspect that was not reported in any of the included studies.

Perhaps an under-appreciated aspect is the patient perspective; these patients are often left with a sense of uncertainty surrounding their prognosis and need for further investigation and interventions [65], although these were not reported in any of the studies included in this review. Therefore, studying what information is conveyed to the patient also seems prudent; specifically, in an era of shared decision making, the presentation of the risk-benefit balance and the involvement of the patient and family in the decision-making process becomes all the more important.

Some limitations of this study should be noted. Most studies included were single-centre retrospective studies, limited by inherent biases. This reflected in the highly heterogeneous meta-analyses and quality assessment results, and as such, caution should be exercised in interpretation of pooled proportions. However, given that the majority of the studies in this field are retrospective, of which some were assessed in our quality assessment tool as "good", we chose to continue to include these in the systematic review and meta-analysis. Especially in a field with high heterogeneity, we found evidence that including multiple study designs is warranted [64]. Furthermore, radiological breakdown of non-PnaSAH into cortical or basal cistern patterns was not feasible with the data available. Timing between ictus and CT was not extracted. SAH blood normally resorbs over time, and a scan at $72 \mathrm{~h}$ suggesting a PnaSAH may well represent the residual blood from a non-PnaSAH. The data is also historical, with many of the studies using DSA as the initial imaging modality; it would be prudent to assess the prevalence of naSAH and delayed diagnosis rates in an era of widespread use of highresolution CTA. It was not within the scope of this review to determine the diagnostic accuracy of the different imaging modes of a diagnostic modality and as such data regarding resolution among other imaging parameters were not extracted. Risk of complications of CTA, DSA and MRI/A was not determined based on data available in our selected studies; however, this is an important aspect to consider against the risk of delayed diagnosis in naSAH patients and particularly those with a perimesencephalic pattern.

\section{Heterogeneity and external validity}

The strengths of this study with regard to external validity include the large pooled population from diverse geographical locations, the primarily uniform definitions to describe groups of bleeding pattern and the agreement with previous studies on the association between bleeding pattern and delayed diagnoses outcomes [33, 56, 62]. However, the reliability of our results is dependent on the quality of data available in the included studies, and selection and recall bias may influence the generalisability of our findings; data was pooled from populations with differing and often unknown baseline characteristics, for example, data regarding use of antiplatelet and anticoagulant drugs were not available. Furthermore, possible interactions among variables associated with post-bleed complications and functional outcomes, such as clinicoradiological severity and bleeding pattern, could not be accounted for as the nature of the data available precluded multivariate or individual patient-level analyses. Significant variation in outcome measures was also observed. All of these are reflected in the large $I^{2}$ values in many of the meta-analyses, and therefore, caution should be exercised in interpreting some of these results. These limitations and high $I^{2}$ statistics highlight the fact that there is significant heterogeneity within the pre-defined subgroups and suggest that decisions about management and further investigation require large volumes of individual patient-level data from carefully curated prospective databases to understand the nuances of how to tailor management to detect occult vascular causes and optimise functional outcomes. There is also a clear need to report studies according to the newly developed set of common data elements and develop a patient-centred core outcome set for data standardisation to allow future homogenous analyses that will benefit both patients and clinicians [60].

\section{Conclusions}

There is much heterogeneity in how patients with spontaneous SAH and negative initial angiographic imaging are investigated and treated. Although there are a higher proportion of patients with favourable functional outcome in the PnaSAH cohort compared to the non-PnaSAH cohort, both cohorts have patients (6.1 and $12.8 \%$, respectively) with unfavourable functional outcomes that may be optimised with better acute management of complications and longer-term rehabilitation. There is a higher rate of delayed diagnoses in the nonPnaSAH cohort. However, with the heterogeneity of initial and delayed neurovascular imaging strategies, it is challenging to attribute the delayed discovery to a single patient aspect, be it clinical or radiological. This systematic review therefore highlights the need for an evidence-based, stratified approach to this patient cohort based upon the initial pattern of bleeding and clinico-radiological status. There is a pressing need for a contemporary large-scale prospective multi-centre observational study that would facilitate the identification of highrisk patients that require comprehensive investigation and management in neuroscience centres with specific neurorehabilitation requirements and potentially low-risk patients that can be managed with more conservative strategies. 
Funding The authors did not receive any external funding for the completion of this study. AC is supported by a Great Ormond Street Hospital (GOSH) Children's Charity Surgeon Scientist Fellowship and the GOSHNational Institute of Health Research (NIHR) Biomedical Research Centre.

\section{Compliance with ethical standards}

Conflict of interest All authors certify that they have no affiliations with or involvement in any organisation or entity with any financial interest (such as honoraria; educational grants; participation in speakers' bureaus; membership, employment, consultancies, stock ownership, or other equity interest; and expert testimony or patent-licencing arrangements), or non-financial interest (such as personal or professional relationships, affiliations, knowledge or beliefs) in the subject matter or materials discussed in this manuscript.

Ethical approval For this type of study, formal ethical approval was not required.

Informed consent For this type of study, formal patient consent was not required.

Open Access This article is distributed under the terms of the Creative Commons Attribution 4.0 International License (http:// creativecommons.org/licenses/by/4.0/), which permits unrestricted use, distribution, and reproduction in any medium, provided you give appropriate credit to the original author(s) and the source, provide a link to the Creative Commons license, and indicate if changes were made.

\section{References}

1. Alen JF, Lagares A, Lobato RD, Gomez PA, Rivas JJ, Ramos A (2003) Comparison between perimesencephalic nonaneurysmal subarachnoid hemorrhage and subarachnoid hemorrhage caused by posterior circulation aneurysms. J Neurosurg 98:529-535

2. Alfieri A, Gazzeri R, Pircher M, Unterhuber V, Schwarz A (2011) A prospective long-term study of return to work after nontraumatic nonaneurysmal subarachnoid hemorrhage. J Clin Neurosci 18: $1478-1480$

3. Al-Mufti F, Merkler AE, Boehme AK, Dancour E, May T, Schmidt JM, Park S, Connolly ES, Lavine SD, Meyers PMet al (2018) Functional outcomes and delayed cerebral ischemia following nonperimesencephalic angiogram-negative subarachnoid hemorrhage similar to aneurysmal subarachnoid hemorrhage. Neurosurgery 82: 359-364 Doi https://doi.org/10.1093/neuros/ nyx 188

4. Andaluz N, Zuccarello M (2008) Yield of further diagnostic workup of cryptogenic subarachnoid hemorrhage based on bleeding patterns on computed tomographic scans. Neurosurgery 62:1040 1046; discussion 1047. https://doi.org/10.1227/01.neu. 0000325865.22011.1f

5. Ball JB, Lukin RR, Tomsick TA, Chambers AA (1985) Complications of intravenous digital subtraction angiography. Arch Neurol 42:969-972

6. Berdoz D, Uske A, De Tribolet N (1998) Subarachnoid haemorrhage of unknown cause: clinical, neuroradiological and evolutive aspects. J Clin Neurosci 5:274-282

7. Beseoglu K, Pannes S, Steiger HJ, Hänggi D (2009) Long-term outcome and quality of life after nonaneurysmal subarachnoid hemorrhage. Acta Neurochir 152:409-416
8. Boswell S, Thorell W, Gogela S, Lyden E, Surdell D (2013) Angiogram-negative subarachnoid hemorrhage: outcomes data and review of the literature. J Stroke Cerebrovasc Dis 22:750-757

9. Caeiro L, Menger C, Ferro JM, Albuquerque R, Figueira ML (2005) Delirium in acute subarachnoid haemorrhage. Cerebrovasc Dis 19:31-38. https://doi.org/10.1159/000081909

10. Caeiro L, Santos CO, Ferro JM, Figueira ML (2010) Neuropsychiatric disturbances in acute subarachnoid haemorrhage. Eur J Neurol 18:857-864

11. Canhão P, Ferro JM, Pinto AN, Melo TP, Campos JG (1995) Perimesencephalic and nonperimesencephalic subarachnoid haemorrhages with negative angiograms. Acta Neurochir 132:14 19

12. Canneti B, Mosqueira AJ, Nombela F, Gilo F, Vivancos J (2015) Spontaneous subarachnoid hemorrhage with negative angiography managed in a stroke unit: clinical and prognostic characteristics. J Stroke Cerebrovasc Dis 24:2484-2490. https://doi.org/10.1016/j. jstrokecerebrovasdis.2015.06.011

13. Cánovas D, Gil A, Jato M, de Miquel M, Rubio F (2011) Clinical outcome of spontaneous non-aneurysmal subarachnoid hemorrhage in 108 patients. Eur J Neurol 19:457-461

14. Dalbjerg SM, Larsen CC, Romner B (2013) Risk factors and shortterm outcome in patients with angiographically negative subarachnoid hemorrhage. Clin Neurol Neurosurg 115:1304-1307

15. Dalyai R, Chalouhi N, Theofanis T, Jabbour PM, Dumont AS, Gonzalez LF, Gordon DS, Thakkar V, Rosenwasser RH, Tjoumakaris SI (2013) Subarachnoid hemorrhage with negative initial catheter angiography: a review of 254 cases evaluating patient clinical outcome and efficacy of short- and long-term repeat angiography. Neurosurgery 72:646-652; discussion 651-642. https://doi.org/10.1227/NEU.0b013e3182846de8

16. Dawkins AA, Evans AL, Wattam J, Romanowski CA, Connolly DJ, Hodgson TJ, Coley SC (2007) Complications of cerebral angiography: a prospective analysis of 2,924 consecutive procedures. Neuroradiology 49:753-759. https://doi.org/10.1007/s00234-0070252-y

17. Delgado Almandoz JE, Jagadeesan BD, Refai D, Moran CJ, Cross DT 3rd, Chicoine MR, Rich KM, Diringer MN, Dacey RG Jr, Derdeyn CP et al (2012) Diagnostic yield of computed tomography angiography and magnetic resonance angiography in patients with catheter angiography-negative subarachnoid hemorrhage. J Neurosurg 117:309-315. https://doi.org/10.3171/2012.4.jns112306

18. de Rooij NK, Linn FHH, van der Plas JA, Algra A, Rinkel GJE (2007) Incidence of subarachnoid haemorrhage: a systematic review with emphasis on region, age, gender and time trends. J Neurol Neurosurg Psychiatry 78:1365-1372. https://doi.org/10. 1136/jnnp.2007.117655

19. DerSimonian R, Laird N (1986) Meta-analysis in clinical trials. Controlled Clinical Trials 7:177-188. https://doi.org/10.1016/ 0197-2456(86)90046-2

20. Duong H, Melançon D, Tampieri D, Ethier R (1996) The negative angiogram in subarachnoid haemorrhage. Neuroradiology 38:1519

21. Ellis JA, McDowell MM, Mayer SA, Lavine SD, Meyers PM, Connolly ES Jr (2014) The role of antiplatelet medications in angiogram-negative subarachnoid hemorrhage. Neurosurgery 75 : $530-535$

22. England RCoSo (2006) National study of subarachnoid haemorrhage. Final report of an audit carried out in 34 neurosurgical units in the UK and Ireland between 14 September 2001 to 13 September 2002. $1-56$

23. Flaherty ML, Haverbusch M, Kissela B, Kleindorfer D, Schneider A, Sekar P, Moomaw CJ, Sauerbeck L, Broderick JP, Woo D (2005) Perimesencephalic subarachnoid hemorrhage: incidence, risk factors, and outcome. J Stroke Cerebrovasc Dis 14:267-271. https:// doi.org/10.1016/j.jstrokecerebrovasdis.2005.07.004 
24. Fontanella M, Rainero I, Panciani PP, Schatlo B, Benevello C, Garbossa D, Carlino C, Valfrè W, Griva F, Bradac GBet al (2011) Subarachnoid hemorrhage and negative angiography: clinical course and long-term follow-up. Neurosurg Rev 34: 477-484

25. Franz G, Brenneis C, Kampfl A, Pfausler B, Poewe W, Schmutzhard E (2001) Prognostic value of intraventricular blood in perimesencephalic nonaneurysmal subarachnoid hemorrhage. $\mathrm{J}$ Comput Assist Tomogr 25:742-746

26. Freeman MF, Tukey JW (1950) Transformations related to the angular and the square root. Ann Math Statist 21:607-611. https://doi. org/10.1214/aoms/1177729756

27. Goergen SK, Barrie D, Sacharias N, Waugh JR (1993) Perimesencephalic subarachnoid haemorrhage: negative angiography and favourable prognosis. Australas Radiol 37:156-160

28. Gross BA, Lin N, Frerichs KU, Du R (2012) Vasospasm after spontaneous angiographically negative subarachnoid hemorrhage. Acta Neurochir 154:1127-1133

29. Heit JJ, Pastena GT, Nogueira RG, Yoo AJ, Leslie-Mazwi TM, Hirsch JA, Rabinov JD (2016) Cerebral angiography for evaluation of patients with CT angiogram-negative subarachnoid hemorrhage: an 11-year experience. AJNR Am J Neuroradiol 37:297-304. https://doi.org/10.3174/ajnr.A4503

30. Hütter BO, Gilsbach JM, Kreitschmann I (1994) Is there a difference in cognitive deficits after aneurysmal subarachnoid haemorrhage and subarachnoid haemorrhage of unknown origin? Acta Neurochir 127:129-135

31. Ildan F, Tuna M, Erman T, Göçer AI, Cetinalp E (2002) Prognosis and prognostic factors in nonaneurysmal perimesencephalic hemorrhage: a follow-up study in 29 patients. Surg Neurol 57:160-165 discussion 165-166

32. Jung JY, Kim YB, Lee JW, Huh SK, Lee KC (2006) Spontaneous subarachnoid haemorrhage with negative initial angiography: a review of 143 cases. J Clin Neurosci 13:1011-1017

33. Kalra Vivek B, Wu X, Matouk Charles C, Malhotra A (2015) Use of follow-up imaging in isolated perimesencephalic subarachnoid hemorrhage. Stroke 46:401-406. https://doi.org/10.1161/ STROKEAHA.114.007370

34. Kang DH, Park J, Lee SH, Park SH, Kim YS, Hamm IS (2009) Does non-perimesencephalic type non-aneurysmal subarachnoid hemorrhage have a benign prognosis? J Clin Neurosci 16: 904 908 Doi https://doi.org/10.1016/j.jocn.2008.10.008

35. Khan AA, Smith JDS, Kirkman MA, Robertson FJ, Wong K, Dott C, Grieve JP, Watkins LD, Kitchen ND (2013) Angiogram negative subarachnoid haemorrhage: outcomes and the role of repeat angiography. Clin Neurol Neurosurg 115:1470-1475. https://doi.org/ 10.1016/j.clineuro.2013.02.002

36. Konczalla J, Kashefiolasl S, Brawanski N, Lescher S, Senft C, Platz J, Seifert V (2016) Cerebral vasospasm and delayed cerebral infarctions in 225 patients with non-aneurysmal subarachnoid hemorrhage: the underestimated risk of Fisher 3 blood distribution. J Neurointerv Surg 8:1247-1252

37. Konczalla J, Kashefiolasl S, Brawanski N, Senft C, Seifert V, Platz J (2016) Increasing numbers of nonaneurysmal subarachnoid hemorrhage in the last 15 years: antithrombotic medication as reason and prognostic factor? J Neurosurg 124:1731-1737. https://doi.org/10. 3171/2015.5.JNS15161

38. Konczalla J, Platz J, Schuss P, Vatter H, Seifert V, Guresir E (2014) Non-aneurysmal non-traumatic subarachnoid hemorrhage: patient characteristics, clinical outcome and prognostic factors based on a single-center experience in 125 patients. BMC Neurol 14:140. https://doi.org/10.1186/1471-2377-14-140

39. Konczalla J, Schmitz J, Kashefiolasl S, Senft C, Seifert V, Platz J (2015) Non-aneurysmal subarachnoid hemorrhage in 173 patients: a prospective study of long-term outcome. Eur J Neurol 22:13291336
40. Konczalla J, Schuss P, Platz J, Vatter H, Seifert V, Guresir E (2015) Clinical outcome and prognostic factors of patients with angiogram-negative and non-perimesencephalic subarachnoid hemorrhage: benign prognosis like perimesencephalic $\mathrm{SAH}$ or same risk as aneurysmal SAH? Neurosurg Rev 38:121-127. https://doi.org/10.1007/s10143-014-0568-0

41. Kong Y, Zhang JH, Qin X (2011) Perimesencephalic subarachnoid hemorrhage: risk factors, clinical presentations, and outcome. Springer, Vienna City, pp 197-201

42. Kostic A, Stojanov D, Stefanovic I, Novak V, Kostic E, BenedetoStojanov D, Veselinovic D (2012) Complications after angiogramnegative subarachnoid haemorrhage: comparative study of pretruncal and nonpretruncal hemorrhage patients. Srp Arh Celok Lek 140:8-13

43. Kumar R, Das KK, Sahu RK, Sharma P, Mehrotra A, Srivastava AK, Sahu RN, Jaiswal AK, Behari S (2014) Angio negative spontaneous subarachnoid hemorrhage: is repeat angiogram required in all cases? Surg Neurol Int 5 https://doi.org/10.4103/2152-7806. 138367

44. Lang EW, Khodair A, Barth H, Hempelmann RG, Dorsch NWC, Mehdorn HM (2003) Subarachnoid hemorrhage of unknown origin and the basilar artery configuration. J Clin Neurosci 10:74-78. https://doi.org/10.1016/S0967-5868\%2802\%2900124-8

45. Li M, Zhu Y, Song H, Gu B, Lu H, Li Y, Tan H, Cheng Y (2017) Subarachnoid hemorrhage in patients with good clinical grade: accuracy of 3.0-T MR angiography for detection and characterization. Radiology 284:191-199. https://doi.org/10.1148/radiol. 2017161469

46. Liberati A, Altman DG, Tetzlaff J, Mulrow C, Gøtzsche PC, Ioannidis JPA, Clarke M, Devereaux PJ, Kleijnen J, Moher D (2009) The PRISMA statement for reporting systematic reviews and meta-analyses of studies that evaluate healthcare interventions: explanation and elaboration. BMJ 339

47. Lin N, Zenonos G, Kim AH, Nalbach SV, Du R, Frerichs KU, Friedlander RM, Gormley WB (2012) Angiogram-negative subarachnoid hemorrhage: relationship between bleeding pattern and clinical outcome. Neurocrit Care 16:389-398

48. Linn FH, Rinkel GJ, Algra A, van Gijn J (1998) Headache characteristics in subarachnoid haemorrhage and benign thunderclap headache. J Neurol Neurosurg Psychiatry 65:791-793

49. Linn FH, Rinkel GJ, Algra A, van Gijn J (1996) Incidence of subarachnoid hemorrhage: role of region, year, and rate of computed tomography: a meta-analysis. Stroke 27:625-629

50. Madureira S, Canhão P, Guerreiro M, Ferro JM (2000) Cognitive and emotional consequences of perimesencephalic subarachnoid hemorrhage. J Neurol 247:862-867

51. Marquardt G, Niebauer T, Schick U, Lorenz R (2000) Long term follow up after perimesencephalic subarachnoid haemorrhage. J Neurol Neurosurg Psychiatry 69:127-130

52. Maslehaty H, Barth H, Petridis AK, Doukas A, Maximilian Mehdorn H (2013) Special features of subarachnoid hemorrhage of unknown origin: a review of a series of 179 cases. Neurol Res 34:91-97. https://doi.org/10.1179/1743132811Y.0000000025

53. Matsuyama T, Okuchi K, Seki T, Higuchi T, Murao Y (2006) Perimesencephalic nonaneurysmal subarachnoid hemorrhage caused by physical exertion. Neurol Med Chir 46:277-281 discussion 281-272

54. Mensing LA, Ruigrok YM, Greebe P, Vlak MHM, Algra A, Rinkel GJE (2014) Risk factors in patients with perimesencephalic hemorrhage. Eur J Neurol 21:816-819

55. Mensing LA, Vergouwen MDI, Laban KG, Ruigrok YM, Velthuis BK, Algra A, Rinkel GJE (2018) Perimesencephalic hemorrhage: a review of epidemiology, risk factors, presumed cause, clinical course, and outcome. Stroke 49:1363-1370. https://doi.org/10. 1161/STROKEAHA.117.019843 
56. Mohan M, Islim A, Dulhanty L, Parry-Jones A, Patel H (2019) CT angiogram negative perimesencephalic subarachnoid hemorrhage: is a subsequent DSA necessary? A systematic review. J Neuroint Surg: Neurintsurg-2019-015051 https://doi.org/10.1136/ neurintsurg-2019-015051

57. Moscovici S, Fraifeld S, Ramirez-de-Noriega F, Rosenthal G, Leker RR, Itshayek E, Cohen JE (2013) Clinical relevance of negative initial angiogram in spontaneous subarachnoid hemorrhage. Neurol Res 35:117-122. https://doi.org/10.1179/1743132812Y. 0000000147

58. Muehlschlegel S, Kursun O, Topcuoglu MA, Fok J, Singhal AB (2013) Differentiating reversible cerebral vasoconstriction syndrome with subarachnoid hemorrhage from other causes of subarachnoid hemorrhage. JAMA Neurol:1-7. https://doi.org/10. 1001/jamaneurol.2013.3484

59. Mukerji N, Holliman D, Baisch S, Noble A, Schenk T, Nath F (2010) Neuropsychologic impact of treatment modalities in subarachnoid hemorrhage: clipping is no different from coiling. World Neurosurg 74:129-138. https://doi.org/10.1016/j.wneu. 2010.05.009

60. National Institute of Neurological Disorders and Stroke (NINDS) Common data elements, unruptured cerebral aneurysms and subarachnoid hemorrhage, https://www.commondataelements.ninds. nih.gov/SAH.aspx\#tab=Data_Standards (Date of access: 04/07/ 2019)

61. Nayak S, Kunz AB, Kieslinger K, Ladurner G, Killer M, Nayak S, Kunz AB, Kieslinger K, Ladurner G, Killer M (2010) Classification of non-aneurysmal subarachnoid haemorrhage: $\mathrm{CT}$ correlation to the clinical outcome. Clin Radiol 65:623-628. https://doi.org/10. 1016/j.crad.2010.01.022

62. Nicolaas AB, Rob JMG, Mahrouz F, Maarten U, Omid SE, Jan DMM, Natasja L, Gert-Jan L, Dijk JMCV (2014) Repeat digital subtraction angiography after a negative baseline assessment in nonperimesencephalic subarachnoid hemorrhage: a pooled data meta-analysis. J Neurosurg 120:99-103. https://doi.org/10.3171/ 2013.9.JNS131337

63. Oda S, Shimoda M, Hoshikawa K, Osada T, Yoshiyama M, Matsumae M (2011) Cortical subarachnoid hemorrhage caused by cerebral venous thrombosis. Neurol Med Chir 51:30-36

64. Peinemann F, Tushabe DA, Kleijnen J (2013) Using multiple types of studies in systematic reviews of health care interventions - a systematic review. PLoS One 8:e85035. https://doi.org/10.1371/ journal.pone. 0085035

65. Persson HC, Tornbom K, Sunnerhagen KS, Tornbom M (2017) Consequences and coping strategies six years after a subarachnoid hemorrhage - a qualitative study. PLoS One 12:e181006. https:// doi.org/10.1371/journal.pone.0181006

66. Prat D, Goren O, Bruk B, Bakon M, Hadani M, Harnof S (2013) Description of the vasospasm phenomena following perimesencephalic nonaneurysmal subarachnoid hemorrhage. Biomed Res Int 2013:1-8

67. Pyysalo LM, Niskakangas TT, Keski-Nisula LH, Kahara VJ, Ohman JE (2011) Long term outcome after subarachnoid haemorrhage of unknown aetiology. J Neurol Neurosurg Psychiatry 82: 1264-1266

68. Qureshi AI, Jahangir N, Qureshi MH, Defillo A, Malik AA, Sherr GT, Suri MFK (2014) A population-based study of the incidence and case fatality of non-aneurysmal subarachnoid hemorrhage. Neurocrit Care 22:409-413

69. Rinkel GJ, Wijdicks EF, Vermeulen M, Hasan D, Brouwers PJ, van Gijn J (1991) The clinical course of perimesencephalic nonaneurysmal subarachnoid hemorrhage. Ann Neurol 29:463468. https://doi.org/10.1002/ana.410290503
70. Rinkel GJ, Wijdicks EF, Vermeulen M, Ramos LM, Tanghe HL, Hasan D, Meiners LC, van Gijn J (1991) Nonaneurysmal perimesencephalic subarachnoid hemorrhage: $\mathrm{CT}$ and MR patterns that differ from aneurysmal rupture. AJNR Am J Neuroradiol 12: 829-834

71. Sprenker C, Jaymin P, Camporesi E, Vasan R, Van Loveren H, Chen H, Agazzi S (2015) Medical and neurologic complications of the current management strategy of angiographically negative nontraumatic subarachnoid hemorrhage patients. J Crit Care 30: 216.e217-216.e211

72. Tatter SB, Crowell RM, Ogilvy CS (1995) Aneurysmal and microaneurysmal "angiogram-negative" subarachnoid hemorrhage. Neurosurgery 37:48-55. https://doi.org/10.1227/00006123199507000-00007

73. Topcuoglu MA, Ogilvy CS, Carter BS, Buonanno FS, Koroshetz WJ, Singhal AB (2003) Subarachnoid hemorrhage without evident cause on initial angiography studies: diagnostic yield of subsequent angiography and other neuroimaging tests. J Neurosurg 98:12351240

74. Tsermoulas G, Flett L, Gregson B, Mitchell P (2013) Immediate coma and poor outcome in subarachnoid haemorrhage are independently associated with an aneurysmal origin. Clin Neurol Neurosurg 115:1362-1365

75. Van Calenbergh F, Plets C, Goffin J, Velghe L (1993) Nonaneurysmal subarachnoid hemorrhage: prevalence of perimesencephalic hemorrhage in a consecutive series. Surg Neurol 39:320-323

76. Walcott BP, Stapleton CJ, Koch MJ, Ogilvy CS (2015) Diffuse patterns of nonaneurysmal subarachnoid hemorrhage originating from the basal cisterns have predictable vasospasm rates similar to aneurysmal subarachnoid hemorrhage. J Stroke Cerebrovasc Dis 24:795-801

77. Westerlaan HE, van Dijk JMC, van Dijk MJ, Jansen-van der Weide MC, de Groot JC, Groen RJM, Mooij JJA, Oudkerk M (2011) Intracranial aneurysms in patients with subarachnoid hemorrhage: CT angiography as a primary examination tool for diagnosissystematic review and meta-analysis. Radiology 258:134-145. https://doi.org/10.1148/radiol.10092373

78. Whiting J, Reavey-Cantwell J, Velat G, Fautheree G, Firment C, Lewis S, Hoh B (2009) Clinical course of nontraumatic, nonaneurysmal subarachnoid hemorrhage: a single-institution experience. Neurosurg Focus 26:E21

79. Willinsky RA, Taylor SM, TerBrugge K, Farb RI, Tomlinson G, Montanera W (2003) Neurologic complications of cerebral angiography: prospective analysis of 2,899 procedures and review of the literature. Radiology 227:522-528. https://doi.org/10.1148/radiol. 2272012071

80. Woodfield J, Rane N, Cudlip S, Byrne JV (2014) Value of delayed MRI in angiogram-negative subarachnoid haemorrhage. Clin Radiol 69:350-356

81. Yu D-W, Jung Y-J, Choi B-Y, Chang C-H (2012) Subarachnoid hemorrhage with negative baseline digital subtraction angiography: is repeat digital subtraction angiography necessary? J Cerebrovasc Endovasc Neurosurg 14:210-216

82. Zhong W, Zhao P, Wang D, Li G, Sun H, Chen H, Huang S, You C (2014) Different clinical characteristics between perimesencephalic subarachnoid hemorrhage and diffuse subarachnoid hemorrhage with negative initial angiography. Turk Neurosurg 24:327-332. https://doi.org/10.5137/1019-5149.JTN.7253-12.1

Publisher's note Springer Nature remains neutral with regard to jurisdictional claims in published maps and institutional affiliations. 